\title{
UCRL-TR-211263
}

LAWRENCE LIVERMORE N A T IO N A L LABORATORY

Final Report: Guided Acoustic Wave Monitoring of Corrosion in Recovery Boiler Tubing

D. J. Chinn, M. J. Quarry, J. L. Rose

April 11, 2005 
This document was prepared as an account of work sponsored by an agency of the United States Government. Neither the United States Government nor the University of California nor any of their employees, makes any warranty, express or implied, or assumes any legal liability or responsibility for the accuracy, completeness, or usefulness of any information, apparatus, product, or process disclosed, or represents that its use would not infringe privately owned rights. Reference herein to any specific commercial product, process, or service by trade name, trademark, manufacturer, or otherwise, does not necessarily constitute or imply its endorsement, recommendation, or favoring by the United States Government or the University of California. The views and opinions of authors expressed herein do not necessarily state or reflect those of the United States Government or the University of California, and shall not be used for advertising or product endorsement purposes.

This work was performed under the auspices of the U.S. Department of Energy by University of California, Lawrence Livermore National Laboratory under Contract W-7405-Eng-48. 


\section{DOE Final Report}

Guided Acoustic Wave Monitoring of Corrosion in Recovery Boiler Tubing

Principal Investigator:

Diane J. Chinn

Lawrence Livermore National Laboratory

P.O. Box 808, L-333

Livermore, CA 94550

Phone: (925) 423-5134

Fax: (925) 424-3215

Email: chinn3@llnl.gov

\section{Co-Investigators:}

Michael Quarry, Lawrence Livermore National Laboratory

Joseph Rose, Penn State University

February 22, 2005 


\begin{abstract}
Corrosion of tubing used in black-liquor recovery boilers is a major concern in all pulp and paper mills. Extensive corrosion in recovery boiler tubes can result in a significant safety and environmental hazard. Considerable plant resources are expended to inspect recovery boiler tubing. Currently, visual and ultrasonic inspections are primarily used during the annual maintenance shutdown to monitor corrosion rates and cracking of tubing. This Department of Energy, Office of Industrial Technologies project is developing guided acoustic waves for use on recovery boiler tubing. The feature of this acoustic technique is its cost-effectiveness in inspecting long lengths of tubes from a single inspection point. A piezoelectric or electromagnetic transducer induces guided waves into the tubes. The transducer detects fireside defects from the cold side or fireside of the tube. Cracking and thinning on recovery boiler tubes have been detected with this technique in both laboratory and field applications. This technique appears very promising for recovery boiler tube application, potentially expediting annual inspection of tube integrity.
\end{abstract}

\title{
INTRODUCTION
}

In the kraft recovery boiler, water-filled tubes constitute the structure of the furnace serving to absorb thermal energy from the furnace. Exposed to combustion on the fireside and filled with pressurized flowing feedwater, recovery boiler wall tubes must withstand large and variable thermal and mechanical stresses. Furnace gas temperatures up to $2500^{\circ} \mathrm{F}$ combined with the harsh molten salt environment can cause premature corrosion on the outer diameter of the recovery boiler wall tubes.

Extensive damage to recovery boiler tubes can result in a significant safety and environmental hazard. Considerable plant resources are expended to inspect recovery boiler tubing. Currently, visual and ultrasonic inspections are primarily used during the annual maintenance shutdown to monitor corrosion rates and cracking of tubing. If corrosion or cracking is detected, tubing must be repaired or replaced during the shutdown.

Guided acoustic waves have been developed as an inspection technique for tubular members for several years. The feature of this acoustic technique is its cost-effectiveness in inspecting long lengths of tubes from a single inspection point. Recent applications on nuclear steam generators have shown that guided acoustic waves can inspect entire cross-sections of tubes over 50 - 75 feet. This technique appears very promising for recovery boiler tube application by expediting annual inspection and possibly providing on-line periodic monitoring of tube integrity. Development of a sensor for monitoring the integrity of recovery boiler tubes during the lifetime of the furnace would allow timely replacement of cracked or corroded tubes.

\section{APPROACH}

Guided acoustic waves are launched from a single position and propagate along the axis of the tube for long distances. Waves are reflected where damage, such as cracks or corrosion, occur. Guided waves fill the entire cross-section of the tube with acoustic energy, so flaws located on the coldside, fireside, inner diameter or outer diameter can be detected. Figure 1 shows the concept of guided wave testing to detect defects on boiler tubing. The ability to 
propagate long distances and inspect $100 \%$ of the volume, including inaccessible areas, makes guided waves a powerful technique for application to boiler tubing.

Many guided acoustic wave modes may propagate in a tube. Each mode has unique characteristics for wave speed, distribution of energy across the thickness, and sensitivity to loading conditions. A successful technique requires that the proper modes be selectively excited. In practice, a single mode must be excited because multiple modes result in several echoes arriving at different times from the same flaw thereby causing difficulty in interpreting data. For boiler tubes, the mode must propagate with minimal sensitivity to water loading conditions and maximum sensitivity to flaws. To selectively excite modes, sensors are designed to propagate waves at the appropriate frequencies and with proper phase characteristics to control the mode generated in the tube.

Our goal in the development of the guided wave technique for boiler tubes is to serve as a screening tool for two types of defects: circumferential cracks at restraints and wall thinning due to corrosion. Guided waves are meant to detect and locate rather than characterize flaws in boiler tubes. It is difficult to precisely characterize flaws using guided waves; flaw sizes cannot be determined without significant error. Hence, a more effective approach is to screen large areas with the guided wave technique and use conventional, localized techniques such as angled shear wave inspection to derive accurate sizing. For screening, creation of a guided wave baseline data set and monitoring changes to the baseline data over the tube lifetime would make identification of damage easier than initial testing with no prior information.

The scope of this investigation was limited to development of a technique for testing during shutdown. On-line techniques are possible but require further development of sensors that are suitable for the high temperature environment.

\section{PROJECT OUTLINE}

Furnace environments present several challenges to current guided wave inspection techniques. In the first year of this project, we researched issues related to implementation of guided wave inspection in the harsh furnace environment. Specific challenges included 1) generation of guided waves using sensors that operate at high temperatures, 2) determining the sensitivity of guided waves to the types of defects expected and 3) assessing thermal and mechanical effects of the furnace environment on guided wave propagation.

A project steering committee was created in the first year to guide the project toward commercial use. Committee members were Peter Ariessohn and Margaret Gorog, Weyerhaeuser, Sandy Sharp, MeadWestvaco, Jacques Brignac, Alstom Power and Peter Thomas, Longview Inspection. The members of the committee represented tube manufacturers, paper mill owners and inspection companies. Valuable input from the steering committee was obtained through periodic meetings.

Initial feasibility studies were conducted on a set of virgin membraned tubes contributed in-kind by $\mathrm{ABB}$ Combustion. The first year assessment proved the feasibility of defect detection using long-distance guided acoustic waves. Initial work also focused on theoretical analysis. 
Theoretical modeling on guided wave mode propagation and power distribution around the tube was performed by Penn State University to analyze sensor design and determine optimal sensor characteristics, such as frequency, loading angle, and length. Lawrence Livermore National Laboratory then used the results to design sensors and develop a complete system to inspect boiler tubing. Next, the sensors were tested on samples that had been pulled out of service to test the technique on real samples and damage. Determination of the sensitivity of guided waves in this application was performed using tube samples from collaborators and other industrial contributors.

Subsequently, sensitivity issues were addressed by narrowing the scope of the investigations to two specific types of defects, cracking at restraints and wall thinning. The scope was narrowed by the Steering Committee to these type of defects based on their high frequency of occurrence and potential for significantly decreasing maintenance shutdown time. Piezoelectric and electromagnetic transducers were evaluated for their sensitivity to the two types of defects. Field tests were conducted at the Weyerhaeuser Prince Albert Plant to demonstrate the technology and determine issues for field use.

\section{FEASIBILITY STUDIES ON VIRGIN TUBES}

Initial feasibility studies were conducted on a set of virgin membraned tubes contributed in-kind by ABB Combustion. Machined defects were placed in the samples to simulate cracking, corrosion, pitting, and wall thinning. The defects were selected by the Steering Committee as common defects in the industry. Defects were placed on the I.D. as well as the O.D. The guided wave technique was able to detect each of the defects with high signal-tonoise. Detection of fireside defects with sensors placed on the coldside was also demonstrated. The membranes were found to have negligible effects on the propagation of guided wave modes. These successful experiments showed the feasibility of guided waves for the inspection of recovery boiler tubing [1].

\section{SENSOR AND SYSTEM DEVELOPMENT}

Theoretical modeling was done by Penn State to determine the optimal parameters of sensors. In an ideal case, a fully encircling axisymmetric sensor generates the guided waves. This produces modes with an axisymmetric power distribution so the same amount of power will impinge on a defect regardless of its circumferential location on the tube. Thus, sensitivity would not depend on location of the flaw. However, recovery boiler tubes prevent a sensor from fully encircling the tube, so a sensor must only load part of the surface with sound. This results in modes that propagate with a nonaxisymmetric distribution across the circumference. Penn State modeled this problem and showed that maximizing the loading angle and tuning frequency will minimize the effects of a nonaxisymmetric distribution and ensure that the full circumference of the tube will have sufficient energy to detect flaws at any circumferential location on the tube [2,3]. Therefore, a probe on the coldside can detect flaws on the fireside [4]. The study modeled the circumferential loading angle, loading length, and frequency and their effect on mode propagation and energy distribution of the mode throughout the tube. Rigorous mathematical description and analysis can also be found in $[2,3,4]$. 
Using the analysis, sensors were designed to optimize the guided wave technique for application to recovery boiler tubing. Numerous guided acoustic wave modes can be excited in the tube. All possible modes of propagation are represented in phase and group velocity dispersion curves. For a tube, the curves are calculated by solving eigenvalues of the wave equation with boundary conditions of free surfaces on the outer and inner diameter of the tubes. The dispersion curves of the first 10 axisymmetric modes of propagation for a 3" outer diameter carbon steel tube with a thickness of 0.210 " are shown in Figure 2. Phase velocity (Figure 2A), is the speed of the phase of the guided wave. Group velocity (Figure 2B), different from the phase velocity in a guided wave, describes the speed at which the guided wave "packet" propagates. Phase velocity is utilized in the design of a guided wave sensor for mode excitation while group velocity is used to identify and locate a defect.

Each point on the dispersion curves is a mode with unique properties. Some modes are sensitive to surface conditions, while some are not. Some modes are more sensitive to corrosion than others. A successful technique relies on exciting modes that maximize sensitivity to the desired flaw (cracking or corrosion). Preferential excitation of the most sensitive modes requires proper sensor design.

Piezoelectric sensors were designed and built based on the theoretical modeling and initial feasibility experiments. An array of piezoelectric elements were built into a Plexiglas wedge material with an angle of incidence of 70 degrees to excite the $L(0,1)$ mode. This mode was found to have optimal sensitivity to cracking and wall thinning in the initial feasibility tests. Frequency is swept and tuned to optimize signal-to-noise from any defect indications. The piezoelectric sensor that was designed for membraned boiler tubing is shown in Figure 3. The sensor consists of an array of 12 piezoelectric elements mounted on a solid lucite wedge that covers $120^{\circ}$ of a 3 " diameter tube. The sensor controls the phase velocity by generating a narrow band of phase velocities around a nominal value obtained from Snell's Law. Possible excitation of guided waves can be determined from Snell's Law assuming the refracted angle is 90 degrees (i.e. propagation is in the direction of the axis of the tube). Therefore, the sensors excite guided waves with a phase velocity $V_{p h}$ given by

$$
V_{p h}=\frac{V_{P l}}{\sin \theta},
$$

where $\theta$ is the incident angle from the wedge and $V_{P l}$ is the longitudinal wave speed in the Lucite wedge. The range of excitation of the wedge is a constant phase velocity at any frequency. For example the wedge in Figure 3 excites all modes in Figure 2A where $V_{p h}=3.1$ $\mathrm{km} / \mathrm{s}$. The wedge determines the phase velocity (vertical axis) of the excited modes. The sensors must be driven by a tone-burst (gated sine wave) to excite a single dominant mode at one time. The narrow frequency band of a tone-burst excites virtually a single frequency on the dispersion curves. The point on the dispersion curve at the frequency and phase velocity chosen will be the mode excited for the given angle of incidence and frequency. An incident angle of 28 degrees $(\mathrm{Vph}=5.8 \mathrm{~km} / \mathrm{s})$ driven at a frequency*thickness of $4 \mathrm{MHz} \mathrm{mm}$ will excited the $\mathrm{L}(0,4)$ mode in Figure 2A. 
For ideal guided wave mode generation and reception, the sensor would fully encircle the tube. Since the loading angle, the angle contacted by the sensor, is restricted to only part of the circumference, the energy distribution is nonaxisymmetric. Maximizing the loading angle makes the acoustic energy more axisymmetric and optimizes generation and reception as shown in the modeling done by Penn State. Hence, the sensors were designed to maximize the circumferential loading angle without adjacent tubes interfering with placement of the sensors. A picture of one of the sensors is shown in Figure 3. For a 3" O.D. boiler tube the maximum loading angle was 120 degrees. This was computed assuming $1 / 2$ " membranes and maximizing the angle such that adjacent tubes would not interfere with placing the sensor on the tube.

In addition to the sensors, the system requires a high power $(5 \mathrm{~kW})$ tone-burst pulser to drive the sensors as well as a broadband superheterodyne receiver to receive the signals. The high power maximizes the propagation length of modes. An RF waveform digitizer records the data digitally. Filters are used as necessary to condition the signal. Graphical-user interface software controls the pulser and receiver settings (number of cycles, frequency, power level, receiver gain, filters, etc.) and acquires and stores the data. The electronics and software are integrated into a single unit that combined with the sensors serves as a guided wave system for performing inspections.

\section{EXPERIMENTAL RESULTS ON REAL TUBES}

Experimental tests were conducted on a variety of samples with both simulated flaws as well as real defects. The samples were tubes that had been taken out of service. In these tests, the piezoelectric array sensor in Figure 3 both sends and receives the guided waves and detects defects in reflection mode. A tone burst generator, capable of sweeping through frequencies to 5 $\mathrm{MHz}$, is used to excite the sensor. Gel couplant is used between the sensor and tube.

\section{Circumferential cracking}

Figure 4 shows a section of boiler tube that was pulled out of service due to circumferential cracking. The crack in Figure 4 located at approximately 9" according to the scale is highlighted by dye penetrant. X-ray computed tomography (CT) was performed on this section to obtain an image of the crack. Circumferential X-ray CT slices of the inner and outer diameter in Figure 5 show that the crack initiated on the I.D. and grew to the O.D. To test guided wave detection on this type of crack, the 12 " section of tube was then welded between two - 10' lengths of tubes according to industry welding guidelines.

A guided wave signal detecting the crack is shown in Figure 6. The tone burst excitation frequency was tuned to $510 \mathrm{kHz}$ to maximize the reflection from the crack. Reflections from the welds also appear before and after the crack reflection. A reflection from the end of the tube, 16 $\mathrm{ft}$. away, also appears in the signal. The results demonstrate long-distance detection of a real circumferential crack by the guided wave technique.

\section{Simulated thinning near a welded attachment}


Another test was performed on a mockup set of tubes to show the ability to resolve flaws in the vicinity of attachments. The mockup set was put together by Alstom Power to test guided wave's ability to detect thinning near attachments. Thinning was simulated near an attachment by machining a 1 " $\mathrm{x} 1$ " area to a depth of 0.066 ", or $30 \%$ of the thickness, into a tube near an attachment. The welded attachment area is shown in Figure 7.

The tube in Figure 7 was tested using the guided wave technique with the sensor approximately 40 " from the thinning and attachment. The simulated thinning was easily detected in reflection mode as shown in the guided wave signal in Figure 8. Detection of the thinning was verified by group velocity calculations of the mode as well as damping the signal on the tube around the thinning.

\section{Stress-assisted corrosion in tangent tubes}

Tests were performed on panels of tubes having areas suspected of having stress-assisted corrosion (SAC). The panels, as shown in Figure 9, were tangent tubes, 24" in length, 2" in diameter and 0.170 " thick. The panels were removed from the sidewall of the boiler above the secondary airports and below the nose arch. Buckeye Technologies contributed these tubes for guided wave testing. Radiographs were taken of the panels to identify tubes with SAC. The depth of the SAC was roughly estimated at about $20 \%$ through-wall. The SAC had several orientations. A typical radiograph of the SAC area of a tube is shown in Figure 9.

The tubes had extremely rough surfaces as a result of many years in service. The surfaces were so rough that standard ultrasonic techniques could not be performed because of insufficient coupling. Profilometry using a $2 \mu \mathrm{m}$ diamond tip stylus showed a 0.030 " peak-topeak variation along the length on the fireside and 0.025 " variation on the coldside.

The surfaces of the tangent tubes had to be aggressively cleaned for guided wave testing. The tubes were cleaned in a 4" $\mathrm{x} 4$ " area to ensure sufficient sound propagation from the sensor into the tube. The cleaning involved a wire brush and took a similar amount of effort as standard cleaning that is done for annual shutdown ultrasonic inspection techniques.

After cleaning guided wave testing was performed on the samples. A typical signal in Figure 11A shows detection of SAC by guided waves. Despite the rough surfaces, the SAC was still detectable. Figure 11B shows the guided wave signal from a tube that was radiographically found to have no cracks. The tangent tubes demonstrate why extremely low detection sensitivity is not desirable in this application. Sensitivities to wall thinning and other flaws that are much below $10 \%$ through-wall would result in the detection of numerous features that are of little interest, e.g. surface roughness, scratches, and general wear. A successful guided wave technique should effectively filter out features that are not of interest. The tangent tubes were rejected for cracking, not for thinning. For these tubes, the technique must detect cracking or deep areas of thinning while not detecting the thousands of small features on the surface.

Aggressively cleaning tubes for inspection is time-consuming and at times impractical. Our commercial partner Alstom Power expressed interest in reducing the amount of cleaning. Electromagnetic acoustic transducers (EMATs) are sensors that modulate a magnetic field to 
create an acoustic wave. EMATs were designed to excite torsional modes in the 60 to $250 \mathrm{kHz}$ region. EMATs consist of a periodic permanent array of magnets that are placed over an electrical coil and use the Lorentz force to generate ultrasound. The electrical coil generates eddy currents in the surface of the tube, and the cross product of this current with the external magnetic field of the magnets creates the ultrasound. The advantage of this method for generation of ultrasound is that EMAT's are much less affected by surface conditions. For comparison, the tangent tube with SAC was tested using a flat EMAT. The guided wave signal using an EMAT send/receive pair is shown in Figure 11C. The arrival time of the reflection from the SAC defect differs from the piezoelectric array transducer (Figure 11A) because a different mode with a different group velocity was excited by the EMAT. Detection of SAC shows the potential of using EMAT sensors on rough dirty tube surfaces. A picture of an EMAT sensor is shown in Figure 12.

\section{Field Test}

A field test was conducted at a shut down boiler to test the guided wave technique under field conditions and determine propagation distances. Figure 13 shows pictures of the system being tested in a recovery boiler at the Prince Albert Mill in Saskatchewan. The tubes in the shutdown boiler were 0.280 " dia. composite tubes. Although the tubes were water washed, a few brushes with a wire brush were still required. The floor tubes were filled with water and the general conditions were the same as during annual maintenance shutdown conditions. Propagation distances of 26' were recorded on both flat and bent tubing. Wall thinning was detected on one tube. The field test showed that guided waves could propagate around bends. Electrical equipment and other operating devices did not produce any noise in the ultrasonic guided wave signals.

\section{CONCLUSIONS}

A guided wave technique was developed as a screening tool for wall thinning and cracking in recovery boilers. Detection of both real and simulated flaws was demonstrated on tubes in the laboratory. Water washing and wire brushing were sufficient preparation for the tube surface when using a piezoelectric transducer. The technique could detect defects with a minimum depth of $20 \%$ wall thickness. Greater sensitivity may not be desirable because it may result in detection of large numbers of less significant features like scratches or surface roughness. EMAT sensors show potential in minimizing surface preparation.

\section{COMMERCIALIZATION AND TECHNOLOGY TRANSFER}

Lawrence Livermore National Laboratory has a patent application pending for the application of this technology to boiler tubes. Alstom Power has written a letter expressing interest in commercialization.

\section{Technology Description}

A guided wave technique was developed as a screening tool for wall thinning and cracking in recovery boilers. Recent accomplishments include: 
a) Detection of real stress-assisted corrosion (SAC) cracking in the laboratory using a piezoelectric array transducer as well as an electromagnetic acoustic array transducer.

b) Detection of thinning to a minimum depth of $20 \%$ wall thickness. Greater sensitivity to thinning may not be desirable because it may result in detection of large numbers of less significant features like scratches or surface roughness.

A guided wave system consists of the following components integrated into a single system:

1. Ultrasonic Guided Wave Sensors - Piezoelectric or EMAT designed for application to recovery boilers

2. High power tone-burst pulser

3. Broadband superheterodyne receiver

4. RF waveform digitizer

5. Data acquisition and control software interface

The pulser, receiver, digitizer, and software interface are integrated into a single PC-based box running Microsoft Windows. The software has a graphical user interface for controlling each device as well as displaying and storing the data.

Current techniques used for inspecting recovery boilers include visual inspection, dye penetrant, and bulk ultrasonic waves. Visual inspection is highly operator-dependent and any flaws must be visible to the eye. Penetrant is useful for surface-breaking cracks where an inspector has access to the surface. Commonly, scaffolding is built inside the boiler for inspectors to take point ultrasonic thickness measurements every 5 to 7 feet to look for wall thinning. These techniques provide only spot checks at various locations of the boiler. Data that is collected is local in nature, testing only a point or a few square inches. Often, areas cannot be tested because there is no practical access. Because each test only covers a small area, doing large areas is very time-consuming. The guided wave technology provides $100 \%$ volume inspection of the boiler in an efficient manner.

Inaccessible areas can be tested from an accessible area. The technique enables a more thorough inspection of the boiler in a more timely fashion. A table comparing the guided wave to current techniques is presented in Table 1 .

Table 1. Comparison of guided wave and current techniques

\begin{tabular}{|l|l|}
\hline \multicolumn{1}{|c|}{ Guided Wave } & \multicolumn{1}{c|}{ Current Techniques } \\
\hline Global in nature; tens of feet of tube & Local in nature; small areas or point-like tests \\
\hline $100 \%$ volume inspection & Sampling at various intervals and locations \\
\hline Inaccessible areas; blind areas, around bends & Accessible areas only \\
\hline Detect flaws on I.D. or O.D. & Often limited to O.D. \\
\hline Fireside and coldside flaw detection & Only on side of access \\
\hline
\end{tabular}




\section{ACKNOWLEDGEMENTS}

The authors would like to acknowledge the support and samples and in-kind contributions given by Peter Ariessohn, formerly of Weyerhaeuser, Sandy Sharp of MeadWestvaco, Margaret Gorog of Weyerhaeuser, Jacques Brignac of Alstom Power, Walter Bursey of Irving Pulp \& Paper and David Streit of Buckeye Technologies.

This work was performed under the auspices of the U.S. Department of Energy by the University of California, Lawrence Livermore National Laboratory under Contract No. W-7405Eng-48.

\section{REFERENCES}

1. Quarry, M.J., Chinn, D.J., Rose, J.L., "Ultrasonic Guided Waves for Recovery Boiler Tubing with Membranes," American Society for Nondestructive Testing 10th Annual Research Symposium, Mar 28, 2001, Denver, CO, p. 47.

2. Sun, Z., Rose, J.L., Quarry, M.J., Chinn, D.J., "Flexural Mode Tuning in Pipe Inspection," Review of Progress in Quantitative Nondestructive Evaluation, Vol. 21A, pp. 262-269, 2002.

3. Quarry, M.J., "Phase Velocity Spectrum Analysis for a Time Delay Comb Transducer for Guided Wave Mode Excitation," Review of Progress in Quantitative Nondestructive Evaluation, Vol. 20A, pp. 861-868, 2001.

4. Rose, J.L., Li, J., Zhou, X., Quarry, M.J., Chinn, D.J., “Ultrasonic Guided Wave Mode Tuning for Limited Access Tube Inspection," Review of Progress in Quantitative Nondestructive Evaluation, Vol. 20A, pp. 164-171, 2001.

5. Quarry, M.J., Chinn, D.J., Rose, J.L., "Feasibility Studies of Ultrasonic Guided Wave Inspection of Boiler Tubing," American Society for Nondestructive Testing Fall Conference 2002, Nov. 4, 2002, San Diego, CA, pp. 219-221. 
FIGURES 


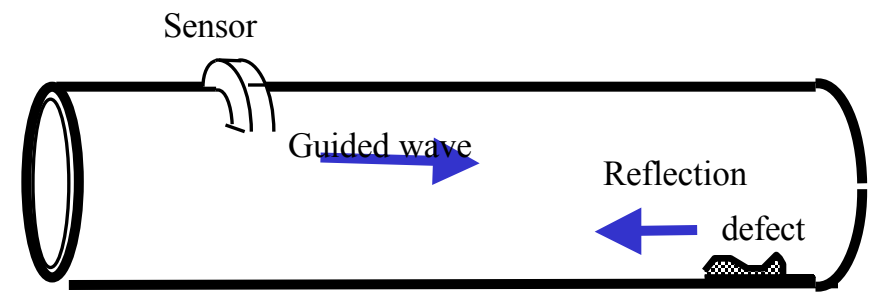

Figure 1. Guided wave testing on tubes uses a sensor to detect defects anywhere on the tube. Acoustic energy spreads from the probe to fill the entire cross-section and reflect from defects on the coldside or fireside.

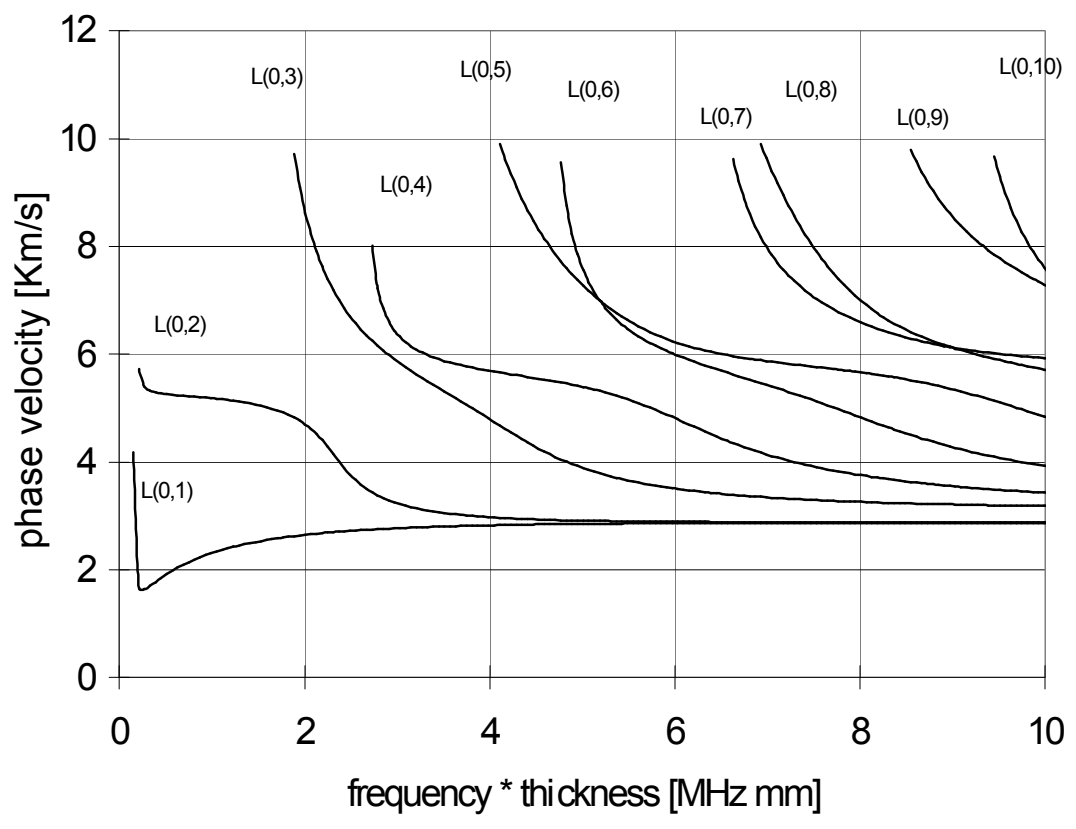

Figure 2A. The first 10 axisymmetric guided wave modes are described by phase velocity dispersion curves for a 3" O.D. carbon steel tube with a thickness of 0.210 ". Phase velocity is important for sensor design. 


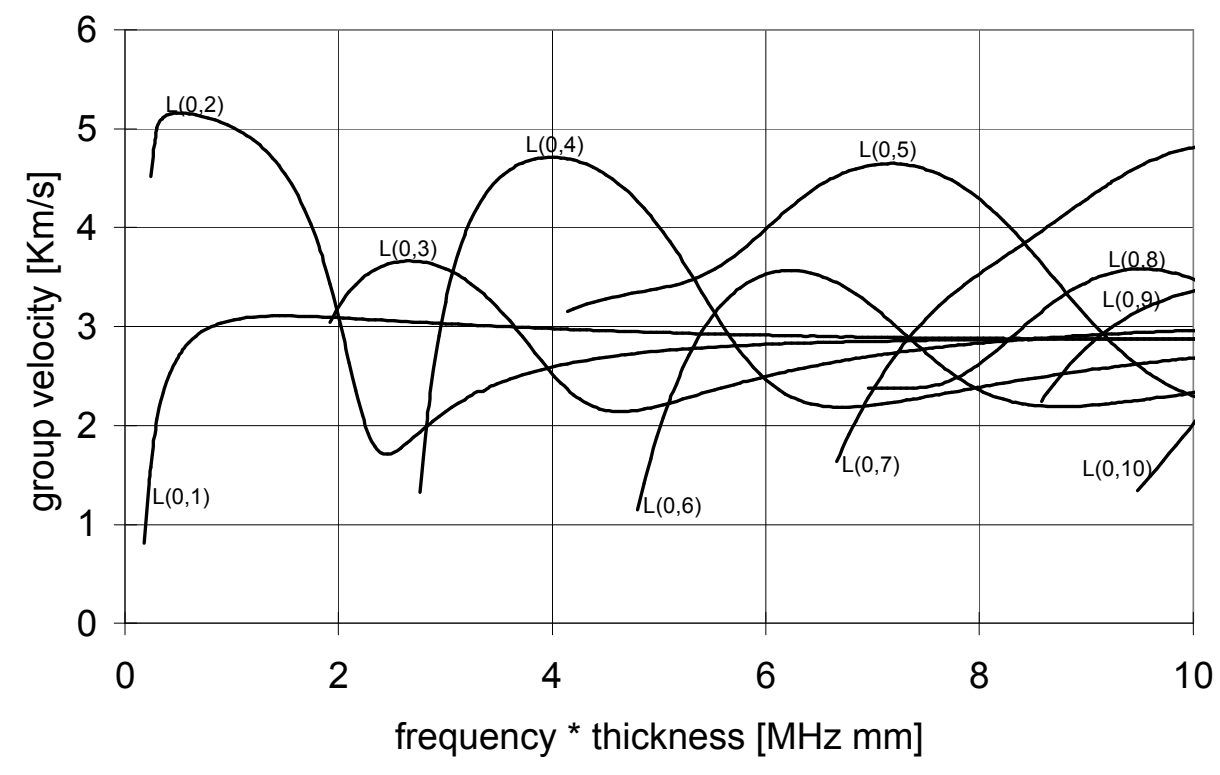

Figure 2B. Group velocity dispersion curves for the first 10 axisymmetric modes in Figure 2A show the velocity of the wave "packet". Group velocity is used to locate flaws.

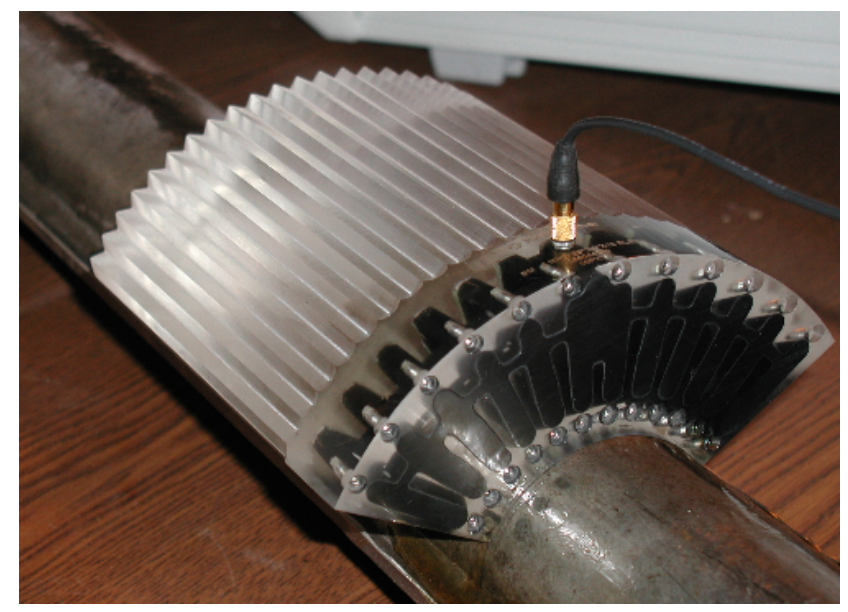

Figure 3. A piezoelectric array sensor for exciting and receiving guided waves in recovery boiler tubing contacts on accessible area of the tube. 


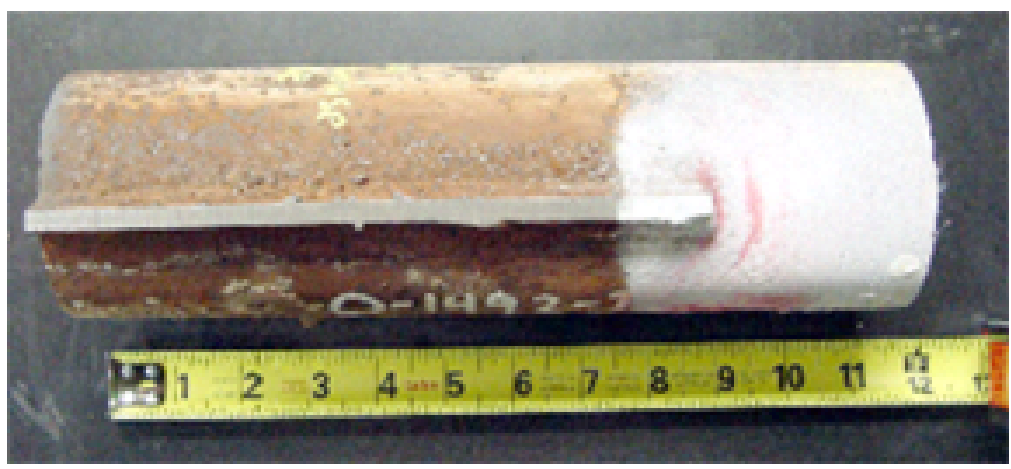

Figure 4. A piece of boiler tube was pulled out of service because of a crack, located just beyond the membrane, is indicated by a dye penetrant. The section was welded between two $10 \mathrm{ft}$. lengths of tube to test guided wave detection.

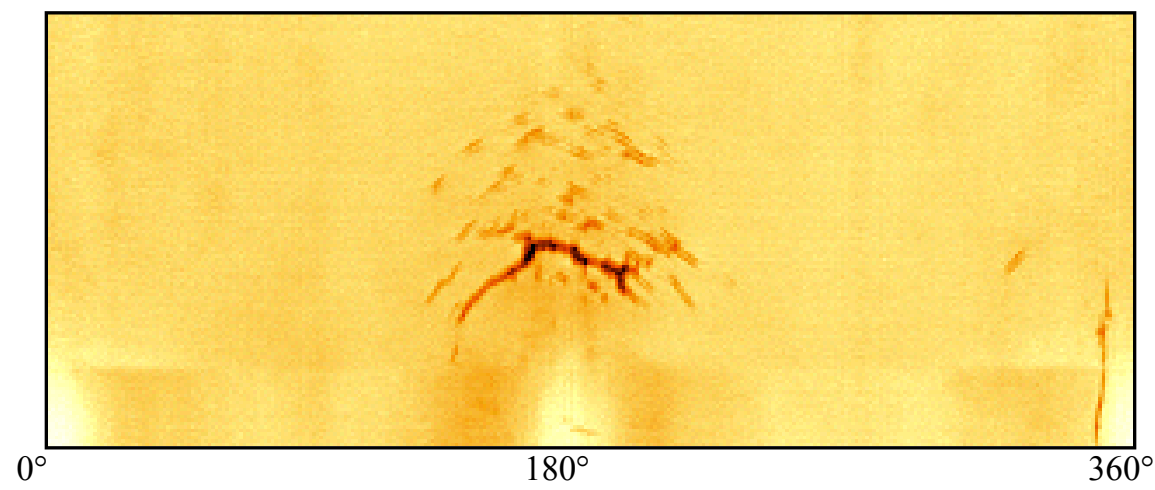

Figure 5A. X-ray CT image of the inner diameter of the circumferential crack specimen shows crack initiations.

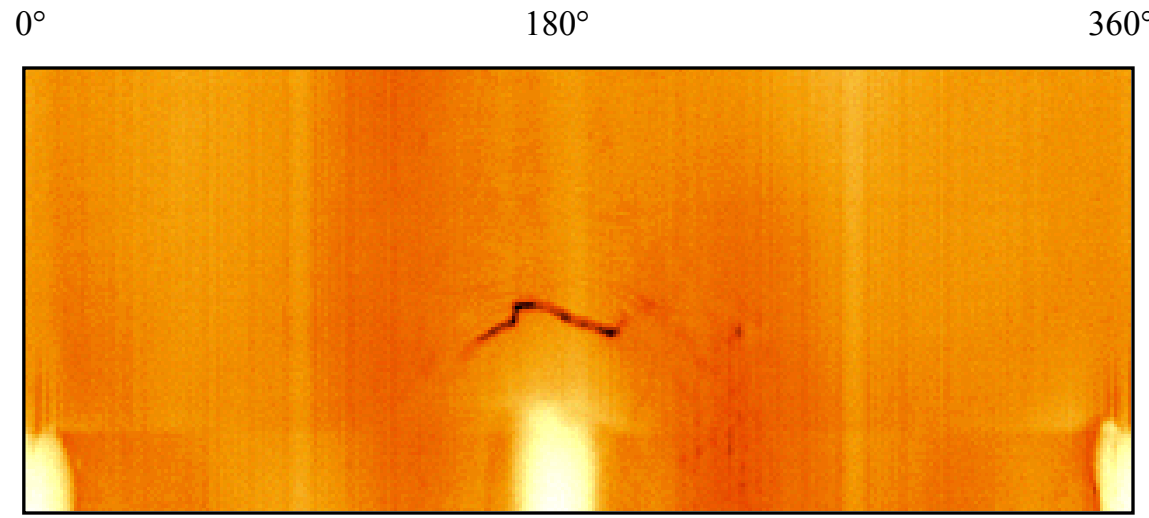

Figure 5B. X-ray CT image of the outer diameter of the circumferential crack specimen shows less crack initiation sites than the inner diameter. 

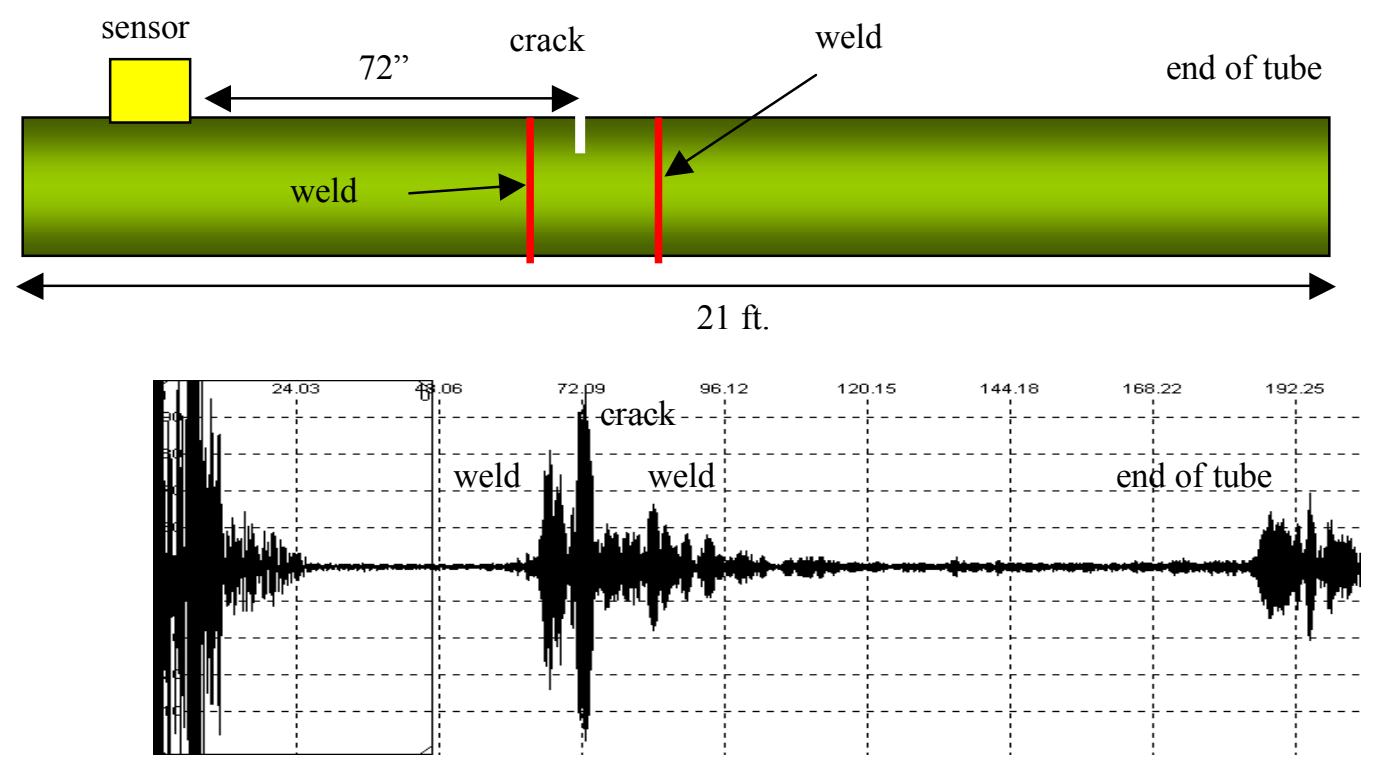

Figure 6. A sample RF waveform shows detection of a crack at 72" and the end of the tube at $16.5 \mathrm{ft}$. 
Simulated thinning

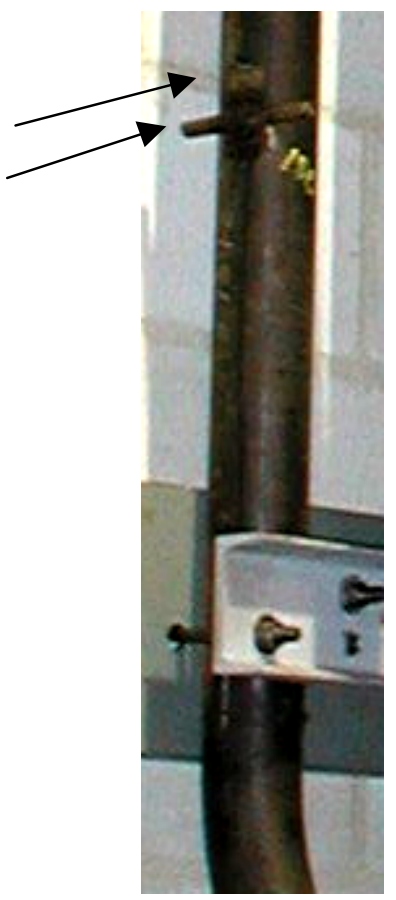

Figure 7. A 1"x 1" area of simulated thinning is located near a welded attachment.

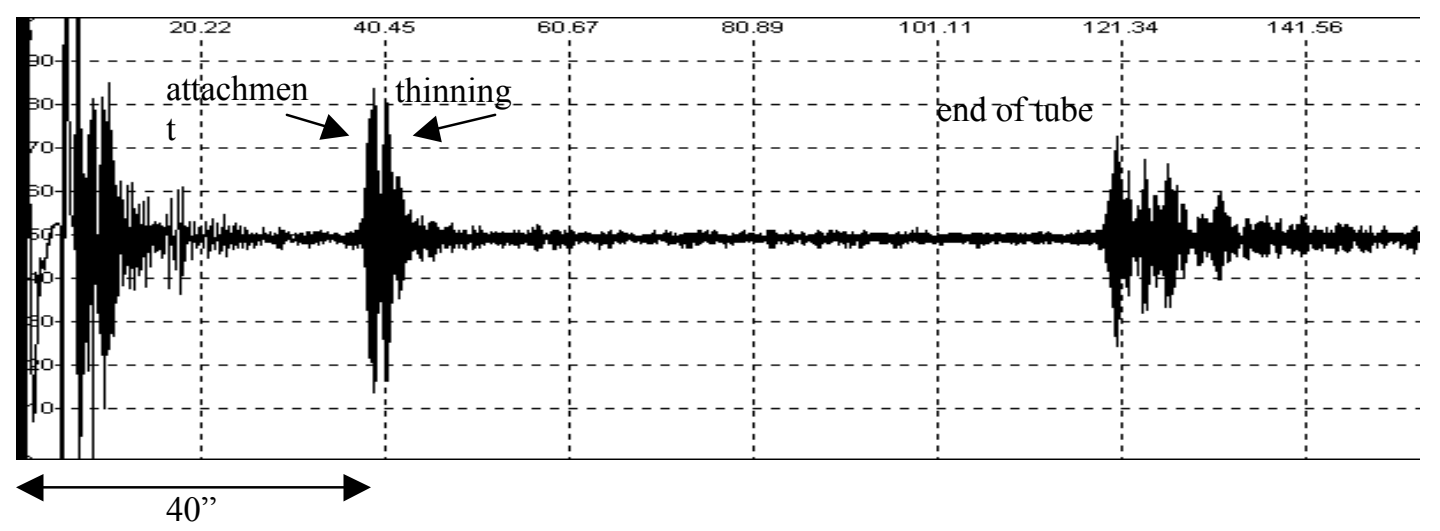

Figure 8. A guided wave signal in reflection mode shows the detection of simulated wall thinning near a welded attachment. 


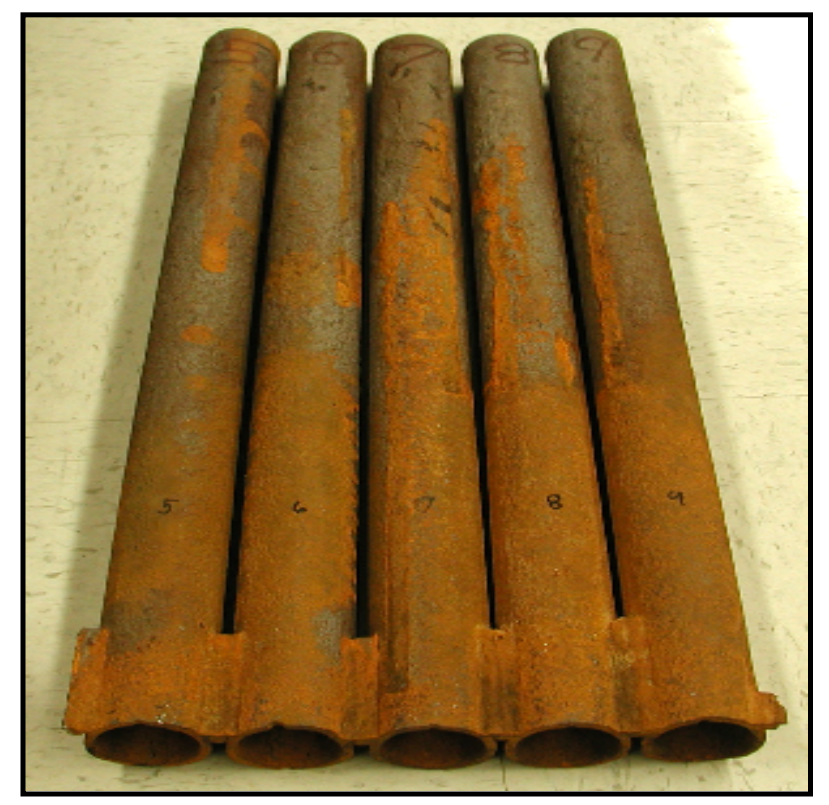

Figure 9. A panel of tangent tubes with suspected stress-assisted corrosion was tested with guided waves.

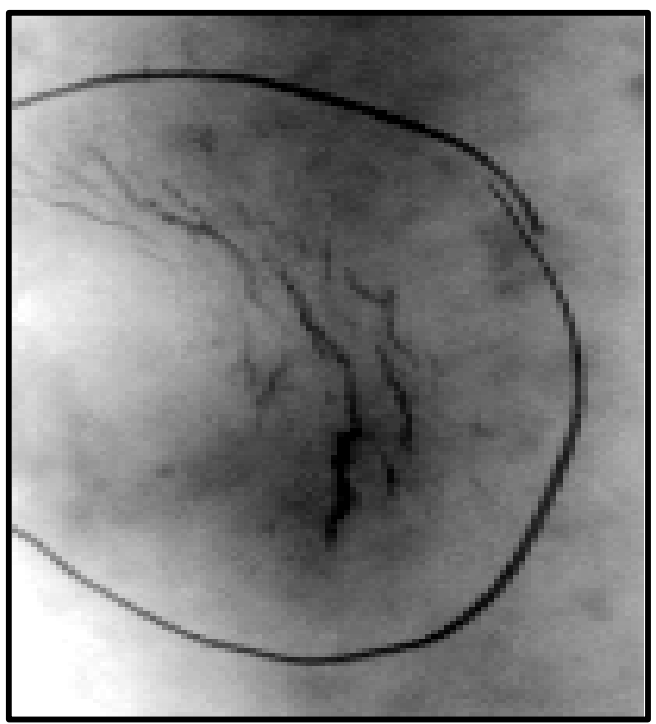

Figure 10. A radiograph of a tangent tube shows stress-assisted corrosion. 


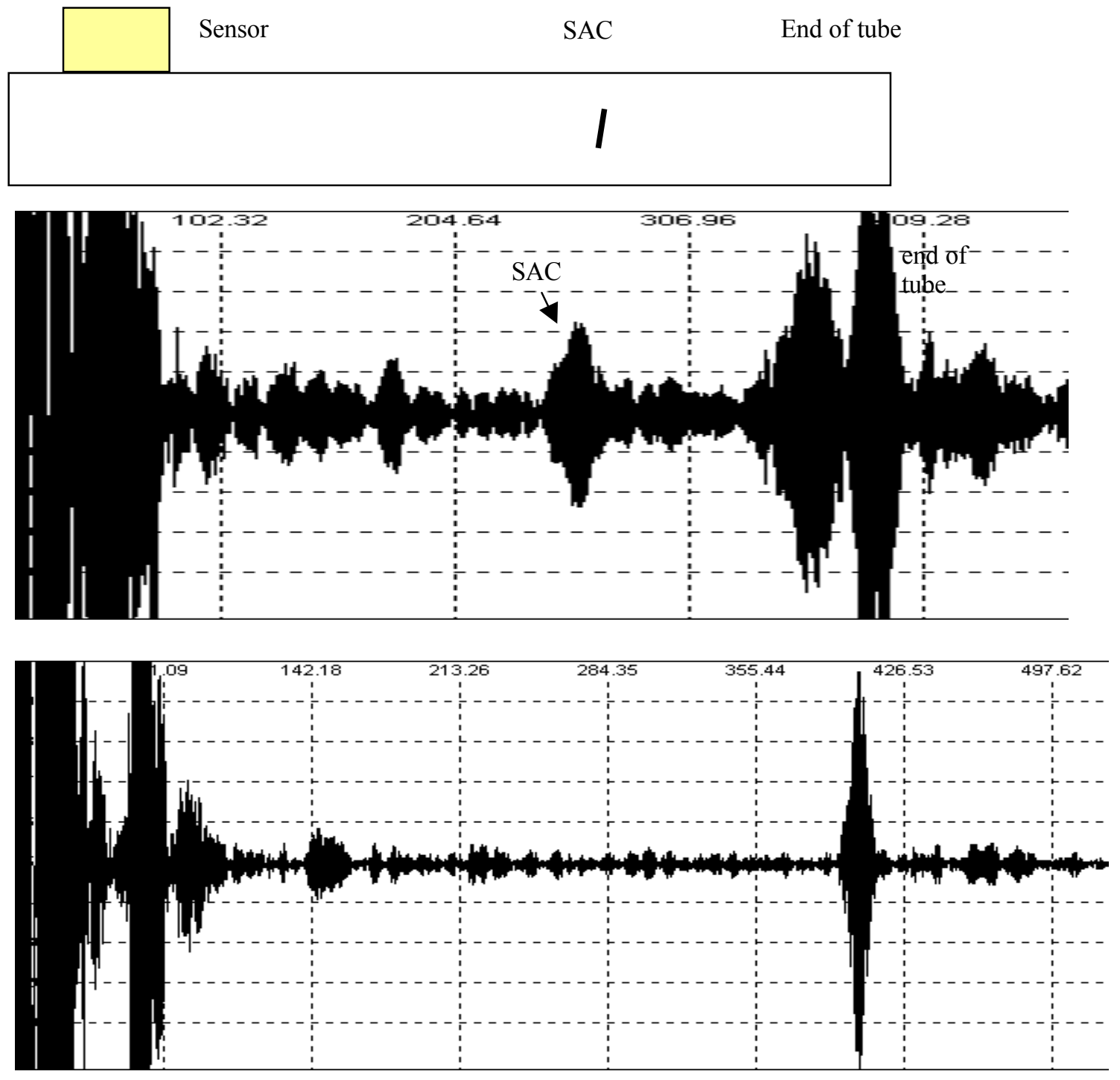

Figure 11B. A sample waveform in a tangent tube with no indication of flaws. 


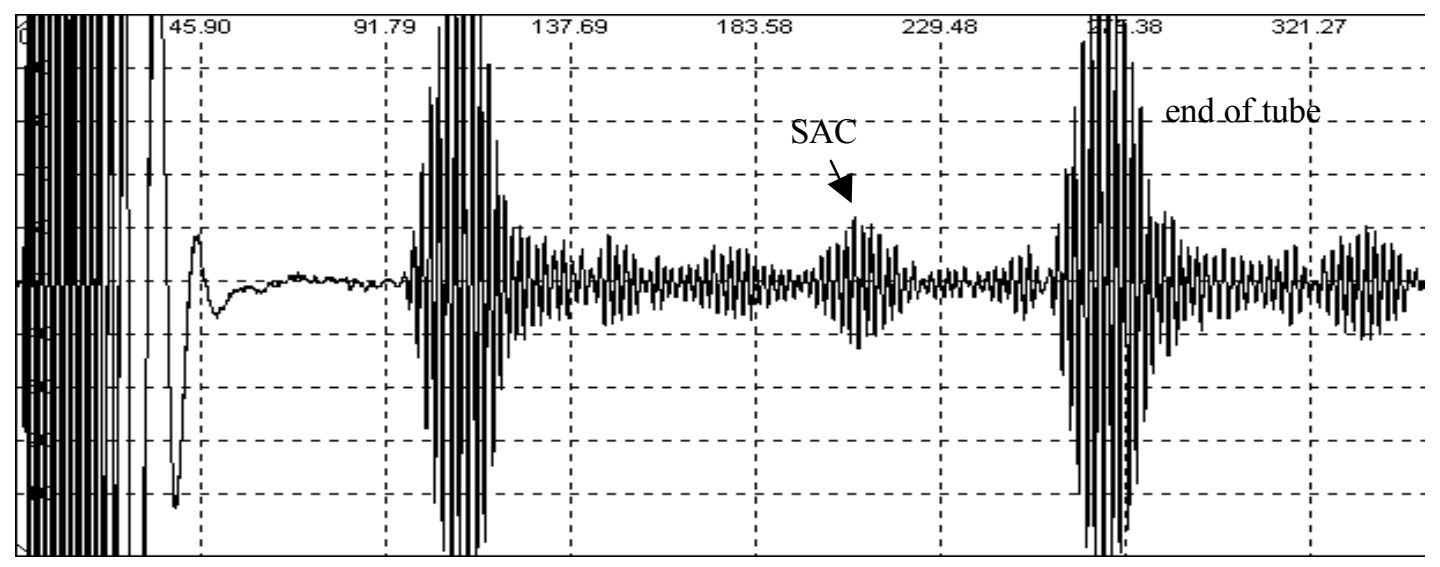

Figure 11C. A guided wave signal generated with EMAT sensors shows detection of SAC.

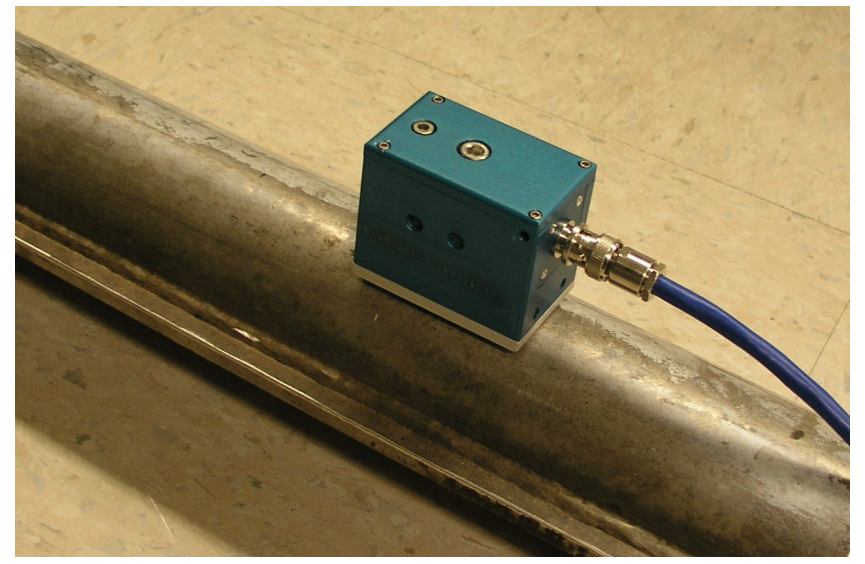

Figure 12. A picture shows a guided wave EMAT sensor on a 3" O.D. coextruded tube. 

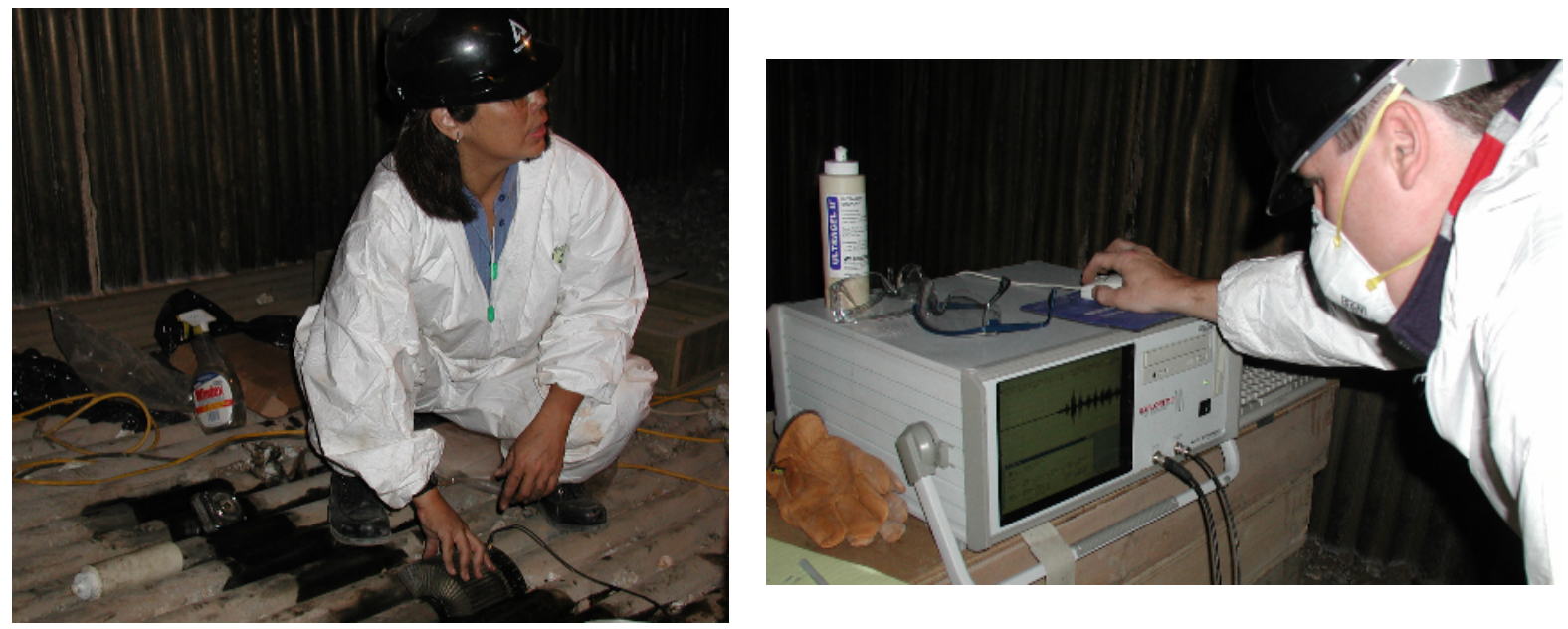

Figure 13. Photos show the field test and demonstration at the Prince Albert mill. 